\title{
Narrativas de jovens surdos sobre seus processos de escolarização no Distrito Federal'
}

\author{
Daniele Nunes Henrique Silva \\ Fabrício Santos Dias de Abreu \\ Universidade de Brasília
}

\section{Resumo}

0 presente trabalho problematiza narrativas de surdos (participantes de atendimento em grupo com enfoque psicoeducacional) sobre seus processos de escolarização. A partir da análise dos dados, destacamos duas categorias analíticas - especificidades da trajetória escolar dos surdos loralismo $\mathrm{X}$ bilinguismol e sentimentos sobre a escola: contradições discursivas. De modo geral, os dados revelam que: al as lembranças dos sujeitos sobre o período escolar remetem a um passado oralista, em que a proibição do uso da Língua Brasileira de Sinais marca fortemente as suas experiências institucionais; e b) a escola é um espaço descrito de forma conflitante e excludente.

Palavras-chave: Narrativa. Memória. Surdez. Bilinguismo. 


\section{Narratives of young deaf people about their schooling processes in the Federal District/Brazil}

This paper problematizes narratives of deaf individuals (participating in a psycoeducacional groupl about their schooling processes. Based on data analysis, we highlight two analytical categories - specificities of the school processes of the deaf persons loralism $X$ bilingualism) and feelings about school: discursive contradictions. In general, the data show that: al the individuals' memories about school refer to an oralist past, in which the prohibition of the use of Brazilian Sign Language heavily marks their institutional experiences; and b) school is described as a conflicting and non-inclusive place.

Keywords: Narrative. Memory. Deafness. Bilingualism.

\section{Las narraciones de jóvenes sordos acerca de sus procesos de escolarización en el Distrito Federal/Brasil}

Este artículo problematiza las narrativas de sordos (que participan de asistencia psico-educacional juntos) acerca de sus procesos de escolarización. A partir del análisis de datos, destacamos dos categorías analíticas - los aspectos específicos de la carrera escolar de los sordos (oralismo X bilingüismo) y los sentimientos sobre la escuela: contradicciones discursivas. En general, los datos muestran que: al los recuerdos de los sujetos sobre la escuela se refieren a un pasado oral, cuando la prohibición del uso de la Lengua de Señas Brasileña marcó fuertemente sus experiencias institucionales; $y$ b) la escuela es un lugar descrito por contradicciones y experiencias excluyentes.

Palabras-clave: Narrativa. Memoria. Sordez. Bilingüismo. 


\section{Introdução}

Um dos interesses investigativos sistematizados ao longo do século $X X$ se debruça sobre as diversas formas de interseção entre o homem e a sociedade. Nessa época, o campo das investigações sobre memória assume relevância particularmente, as discussões teóricas sustentadas por L.S. Vigotski (2000) e Halbwachs (1990), que apontam caminhos originais de tratamento conceitual ao deflagrar a interdependência entre o social e o individual.

A preocupação central desses autores, apesar das distintas posições epistemológicas, diz respeito à composição de um campo argumentativo em que a memória deixa de ser pesquisada de forma atomística, como função isolada do Sistema Nervoso Central (SNC). Nesse escopo, dois aspectos merecem atenção especial na reconfiguração do campo de estudo: um se refere à dinamicidade do funcionamento psicológico superior, sendo a memória estudada na inter-relação com as outras funções psíquicas superiores (imaginação, emoção, atenção etc.), e o outro está associado a sua gênese social. (Silva, Sirgado \& Tavira, 2012)

Vigotski (2000) parte do pressuposto de que a especificidade humana só pode ser explicada em razão do advento do trabalho social, mais detalhadamente da necessidade de organização social para a sobrevivência. Suas ideias, ancoradas nas teses marxistas sobre a constituição do homem, indicam que o funcionamento psíquico de ordem superior (incluindo a memórial está substanciado pelos elos mediadores de organização das ações humanas na natureza. Para ele, a intervenção no ambiente natural promoveu a consolidação de práticas culturais, a criação de instrumentos e a construção coletiva de esferas simbólicas para representar e interpretar o mundo. Por meio da linguagem e da palavra, por exemplo, o mundo passou a ser humanamente pensado, imaginado, percebido, memorizado e narrado.

Segundo Vigotski (2000), há dois tipos de memória: a memória natural, atrelada às percepções do ambiente externo e seus estímulos (funcionamento psíquico elementar), e a memória mediada, estruturada por signos - mais especificamente, a palavra (funcionamento psíquico de ordem superior). A relação entre memória e linguagem merece atenção especial do autor. Em suas pesquisas com crianças e adultos, Vigotski observa diferentes modos de memorizar e relaciona o ato de lembrar à maneira de usar os signos e apropriar-se deles. A palavra, portanto, é o elemento fundamental para a organização da memória humana e, visto que o signo é vinculado às práticas coletivas, a memória passa a ser entendida como atrelada às determinações históricas, culturais e dinâmicas discursivas.

Halbwachs (1990), em meados do século XX, parece também relevar o plano cultural como fundamental para os estudos da memória. Contrariando as 
tendências acadêmicas individualistas sobre o estudo da mnemônica, o autor desenvolve o conceito de memória coletiva e sua relação com a memória individual. Sua maior preocupação é discutir a relação entre indivíduo e sociedade, rompendo com uma visão dicotômica de mundo. Para tanto, busca abordar a consciência social a partir da memória, investindo numa análise que relaciona a lembrança aos contatos e encontros sociais. Isso significa dizer que 0 ato de lembrar ocorre porque alguém lembrou ou tem que ser lembrado. A recordação se dá pelos outros e para os outros.

Desse modo, Halbwachs (1990) propõe analisar a memória numa dimensão interpessoal e o ato de lembrar como vinculado a determinantes e instituições sociais - a família, a classe social etc. As lembranças, portanto, estão atreladas aos modos de inserção nos grupos e ao lugar que se ocupa no grupo - a posição do sujeito que lembra. A memória individual está compreendida na memória coletiva, pois as noções e as imagens construídas subjetivamente são espectros do campo social. 0 autor sugere que as lembranças estão inscritas em quadros sociais comuns aos homens de um mesmo grupo. Há um contínuo movimento entre esses quadros, pois eles são cambiantes, permitindo, quando se lembra, a passagem de um para o outro.

Pode-se afirmar, com base nesses princípios, que aquilo de que se lembra e a forma como se lembra são questões relacionadas ao âmbito social, e essas condições precisam ser investigadas. Ao narrar suas memórias, por exemplo, o sujeito se coloca como autor de sua história, criando a si próprio na e pela linguagem. Para Kramer (2007), essa forma de posicionamento biográfico, viabilizada pela memória e pela narrativa, permite resgatar o passado, por meio de uma compreensão diferenciada da história, e revisar o presente, que adquire nova significação.

\section{Lembrar e narrar: focalizando modos de narrativizar a experiência}

A necessidade de narrar é ontológica. Desde os tempos mais remotos, as dimensões do vivido, sentido e realizado são contadas entre os homens. A noção de perpetuação, continuidade, herança está visceralmente arraigada aos fatos narrados e lembrados. A estruturação de narrativas é, portanto, uma condição humana que redimensiona as relações com a natureza e a cultura. Por meio delas, a coletividade, o outro e a história são acessados. Marcas e pistas são deixadas nas palavras, que traduzem tradições. Crenças, valores e possibilidades de existir se fazem presentes, atuantes no e pelo discurso.

De acordo com Lopes de Oliveira (2012), tem crescido o empenho investigativo 
sobre a temática das narrativas. Para a Lopes de Oliveira (2012, p. 369), a narrativa pode ser focalizada como objeto ou método de pesquisa, configurando-se em um modo específico de “canalização de experiências, organização da memória coletiva, constituição das memórias sociais de comunidades e da própria coerência biográfica do narrador". De fato, aquilo que uma pessoa narra é revelador da maneira de organização de um grupo dentro de um contexto histórico. Mas, ao mesmo tempo (e contraditoriamente), é uma posição única, autoral e biográfica de como cada pessoa se situa nessa (sua) historicidade. A produção de uma narrativa funde o nós e o eu no texto, seja ele oral, escrito ou imagético.

Nessa linha argumentativa, podemos inferir que o conteúdo e a forma de narrar podem ser investigados em função do impacto que produzem no desenvolvimento ontogenético. Narrar e lembrar, como componentes do vivido (real e/ou fantástico), são dimensões da formação subjetiva. Elas nos mostram como nos tornamos humanos, como nos apropriamos da experiência alheia e a convertemos em algo que produz sentido pessoal e nos constitui (Silva, Sirgado e Tavira, 2012; Smolka, 2000). Sobre isso, Lopes de Oliveira (2012, p. 370) destaca: “[...] narrativizar a experiência é mais que enunciar em primeira pessoa textos sociais; envolve sempre agregar à trama dos discursos um plus de sentido subjetivo".

A partir daí, questões conceituais desdobram-se em várias direções: como a experiência de narrar sobre si recompõe elementos da historicidade coletiva? Como fios que vão se entretecendo, como nós que vão articulando lembranças e histórias, o que a narrativa permite entrever?

Debruçando-se sobre esses aspectos epistemológicos mais gerais, o presente artigo busca resgatar as memórias e os textos biográficos de surdos sobre seus processos de escolarização. É a biografia do narrador que nos interessa aqui. Indagamos: o que e como os surdos narram a respeito de suas vivências escolares? Como, por meio de suas biografias narradas, é possível reconfigurar trajetórias subjetivas esquecidas e, comumente, apagadas do discurso educacional hegemônico?

\section{Sobre a história da educação dos surdos: breve retrospectiva}

Do período que se estendeu do final do século XIX até o final do século XX, a educação de surdos se baseou no modelo oralista. Tal princípio filosófico educacional partia do pressuposto de que o mais importante para o surdo era adquirir a língua oral, mesmo que para isso ele tivesse de ser submetido a um processo penoso de aprendizagem. Para os oralistas, o uso de técnicas diversas de oralização era a forma adequada de resolver o problema da integração social 
dos sujeitos acometidos pela surdez.

Conforme salienta Skliar (2006), a orientação da educação das crianças surdas com o único objetivo de aquisição da língua oral já havia se manifestado em outros momentos históricos, mas assumiu centralidade e se radicalizou no período pós-1880 (Congresso de Milão) ${ }^{2}$. A língua de sinais foi reprimida física e psicologicamente, e o surdo passou a ser analisado sob a ótica do modelo clínicoterapêutico. Tal orientação reduziu a problemática da surdez à esfera patológica e à medicalização.

Assim, no século XX, a oralização ocupou o lugar privilegiado da educação de surdos e a língua de sinais foi negligenciada na maior parte das escolas brasileiras. Seu uso e divulgação entre os surdos eram entendidos como um fator de atraso para o desenvolvimento, limitando suas potencialidades de integração social. Acreditava-se que a língua de sinais era precária em suas funções representativas e de abstração. (Silva, 2002)

Nessa linha, a escolarização se resumiu à possibilidade de aquisição da língua oral e a escola tornou-se um local propício para o treinamento labial, uma esfera de adaptação do surdo à comunidade majoritária ouvinte. As disciplinas escolares ocupavam um segundo plano de interesse, o que ocasionava uma queda significativa no nível de escolarização dos surdos. Sobre isso, Goldfeld (1997, p. 35) nos fala:

Ao colocar o aprendizado da língua oral como objetivo principal na educação dos surdos, muitos outros aspectos importantes para o desenvolvimento infantil são deixados de lado. Apenas os profissionais que igualam o conceito de língua oral como o conceito de linguagem podem acreditar que os anos em que a criança surda sofre atraso de linguagem e bloqueio de comunicação lo que é inevitável quando the oferecem apenas a língua oral como recurso comunicativol não prejudica o seu desenvolvimento.

A visão patológica sobre a surdez implicou a criação de estratégias pedagógicas que buscavam a reparação e a correção dos problemas advindos da deficiência. Objetivava-se impor aos alunos o que thes deixava "incompletos": a fala, frequentemente, afetada pela perda auditiva. 0 espaço escolar configurou-se em um ambiente hospitalar reabilitador, em que a pessoa surda se movia no circuito delimitado e pautado pela doença.

Dessa forma, o passado recente das questões relacionadas aos surdos foi marcado pelo olhar de uma sociedade injusta, desigual e autocrática. Essa

2. Nesse congresso ocorreu uma votação, entre ouvintes, com o intuito de estabelecer a melhor estratégia pedagógica para a educação de surd́os. A partir de então, foi proibido oficialmente o uso da língua de sinais no processo instrucional.' 
sociedade relegou o problema da surdez à ótica da incapacidade, colocandose, não poucas vezes, insensível às necessidades desse grupo. Perlin (2005), ao se referir à história dos surdos, indica que ela foi marcada pela violência e pela exclusão. Nas palavras da autora, constata-se que ocorreu a

[...] eliminação vital dos surdos, a proibição do uso da língua de sinais, a ridicularização da língua, a imposição do oralismo, a inclusão do surdo entre os deficientes. Tudo isso tem se constituído como trucidamento da identidade surda, em surdocídio provocado pelo modelo de identidade ouvinte [...]. (Perlin, 2005, p. 79)

A partir da década de 1960, a surdez deixou de ser monopólio de pesquisas atreladas aos espaços terapêuticos e passou a ser discutida por profissionais das Ciências Humanas e Sociais. Antropólogos, linguistas, sociólogos etc. iniciaram um novo campo investigativo, compreendendo o surdo em sua especificidade cultural. Eles perceberam que os surdos formavam uma comunidade cujo valor agregador era a língua de sinais.

Nessa época, o linguista William Stokoe descobriu que a língua de sinais possuía sintaxe e léxico independentes, funcionais, tão eficientes como qualquer língua falada. Para ele, a língua de sinais era reveladora de valores culturais, hábitos e modos de socialização próprios de um grupo específico. A partir daí, paulatinamente, os estudos sobre a surdez foram se deslocando de uma concepção reabilitadora para uma ênfase cultural, em que a língua de sinais passou a ser analisada em seu aspecto linguístico, como sistema de comunicação da comunidade surda. Nesse movimento, foram privilegiadas pesquisas sobre a cultura surda, a identidade bicultural e o bilinguismo (Skliar, 2010). Os pesquisadores entenderam que a surdez era uma experiência visual produtora de outras formas de representação do mundo.

Isso significa dizer que os trabalhos sobre surdez de ênfase socioantropológica debruçaram-se em formulações conceituais que questionaram o colonialismo a que eram submetidas as minorias linguísticas. Ao longo dos últimos anos, por exemplo, foram propostas reformulações nas metodologias educacionais para surdos, por meio de uma recondução das políticas de inclusão. No eixo das reivindicações, o debate esteve sempre atrelado à centralidade da língua de sinais e seu acesso. Sobre isso, argumenta Skliar (2006, p. 102-103):

A participação na comunidade surda se define pelo uso comum da língua de sinais, pelos sentimentos de identidade grupal, o auto-reconhecimento e identificação como surdo, o reconhecer-se como diferentes, os casamentos endogâmicos, fatores estes que levam a redefinir a surdez como uma diferença e não como uma deficiência. [...] 
A língua de sinais anula a deficiência e permite que os surdos consigam, então, uma comunidade linguística minoritária diferente e não um desvio da normalidade.

Nessa direção, Behares (1989), Góes (2002), Kelman (2012), Lacerda (2006), Silva $(2002,2006)$ e Souza $(1996,1998)$ defendem que toda criança surda deve: a) adquirir (o mais precocemente possível) a língua de sinais e b) interagir cotidianamente com surdos que fazem uso dessa língua lassim como acontece com qualquer criança ouvinte em fase de aquisição linguístical.

Para Perlin (2010), a educação de surdos está, aos poucos, saindo do domínio oralista, precisando (ainda) se livrar de alguns preconceitos; entre eles, o de querer fazer do surdo um ouvinte. Segundo a autora, a educação tem que caminhar no sentido da construção identitária do surdo.

Esses aportes conceituais se articularam com uma filosofia educacional para surdos contrária às práticas que ecoaram pelos corredores oralistas. Eles partem do pressuposto de que a língua de sinais tem o mesmo estatuto linguístico das línguas orais e de que o surdo é, por condição cultural, bilíngue - portanto, o bilinguismo deve nortear a sua educação. Em síntese, a língua de sinais deixou de ser entendida como um obstáculo e transformou-se em condição fundamental para a inclusão do surdo, passando a ser considerada uma instância de linguagem não vocal. (Góes, 2002)

\section{Bilinguismo e biculturalidade: especificidades da escolarização do surdo}

A discussão que envolve uma língua depara, inevitavelmente, com a problemática em torno de uma cultura. Estar dentro de uma cultura é vivenciar fronteiras, sejam elas linguísticas ou culturais. Os surdos nascem imersos em um contexto bicultural, em uma relação de fronteira com a língua oral e a língua de sinais, consolidando uma comunidade linguística minoritária. Ser surdo é ser bilíngue; é dialogar num processo de permanente inclusão e exclusão entre duas modalidades linguísticas. Dessa forma, uma das interfaces da política do bilinguismo se concentra em assegurar o direito à educação em língua de sinais como língua materna.

Conforme dito anteriormente, nas últimas décadas, a educação de surdos passou por uma forte e promissora transformação. 0 abandono progressivo do modelo oralista e o aumento das diferentes modalidades e compreensões de filosofias bilíngues e inclusivistas consolidaram novas políticas formativas e uma revolucionária forma de entender a cultura surda. 
Apesar dos avanços, parece oportuno analisar os processos de escolarização de surdos que viveram esse período de transição entre abordagens educacionais (do oralismo para o bilinguismo), a partir de suas trajetórias de vida. Essa tarefa visa dar visibilidade a um contingente considerável de jovens surdos que experimentaram peculiaridades e adversidades em suas trajetórias acadêmicas (nos últimos 20 anos), em razão da ausência/emergência da língua de sinais no ambiente educacional.

Buscando compreender essas mudanças na educação dos surdos, o presente trabalho investiga: o que narram os surdos jovens e adultos sobre as suas vivências escolares? O foco é analisar, a partir de fragmentos discursivos de um grupo de surdos, como eles vivenciaram seus processos de escolarização inseridos na complexidade de filosofias educacionais antagônicas le, por vezes, conflitantes). Para tanto, estruturamos um desenho metodológico coerente com as problematizações teóricas levantadas ao longo da revisão bibliográfica, em que a escuta das narrativas dos sujeitos é um elemento central considerado na análise.

\section{Metodologia de pesquisa e atendimento}

A presente pesquisa se pauta nos preceitos da abordagem qualitativa para guiar o processo de análise e construção dos dados. A ênfase está na interpretação em lugar da mensuração e na descoberta em vez da constatação. Valorizamos a indução ao longo da intervenção para coleta de dados e assumimos a posição de que fatos e valores estão relacionados à produção de conhecimento dos pesquisadores em contato com o campo (André, 2002). Nesse sentido, trabalhamos com descrições, comparações e interpretações analíticas baseadas na produção enunciativa dos sujeitos pesquisados e nas relações interdiscursivas emergentes no campo. Evitamos, portanto, hipóteses preestabelecidas.

Conforme poderá ser visto adiante, observamos, primeiramente, o grupo de surdos, suas necessidades e seu interesse de temática. Em seguida, identificamos os elementos recorrentes nas enunciações, tendo como foco as narrativas sobre os processos de escolarização.

\section{Caracterização do campo}

0 grupo de surdos investigados participa, desde o segundo semestre de 2010, do projeto de pesquisa Surdez e Sofrimento Psíquico: em busca de um cuidado a partir de uma abordagem psicoeducacional, desenvolvido no CAEP (Centro de Atendimento 
e Estudos Psicológicol, vinculado ao Instituto de Psicologia da Universidade de Brasília. $^{3}$

Tal projeto objetiva oferecer atenção profissional, com uma equipe multidisciplinar (psicólogos, pedagogos, linguistas e profissionais de áreas afins), para acompanhamento dos surdos adultos, tendo como meta melhorar a qualidade de suas vidas. 0 atendimento psicoeducativo era quinzenal, em grupo, e propunha a atribuição de novos sentidos às experiências biculturais. Ele era feito por uma psicóloga, um pedagogo e uma intérprete de Libras, que, por meio de conversas, do trabalho com palestras, filmes etc. e de outros tipos de intervenção psicológica Itais como dinâmicas de grupo, mobilização de vivência de afeto e trabalho psicoterapêutico de sofrimentos emergentes), problematizavam as experiências relevantes para o grupo.

Os dados aqui apresentados correspondem ao material coletado no segundo semestre de 2010, em um total de 7 atendimentos realizados com um grupo formado por 5 surdos adultos, com conhecimentos heterogêneos sobre a língua de sinais. São eles ${ }^{4}$ :

- Artur (19 anos): início da escolarização aos 3 anos; primeiro contato com a Libras aos 8 anos;

- Luíza (18 anos): início da escolarização aos 2 anos; primeiro contato com a Libras aos 6 anos;

- Carlos (24 anos): início da escolarização aos 4 anos; primeiro contato com a Libras aos 18 anos;

- Fábio (29 anos): início da escolarização aos 18 meses; primeiro contato com a Libras aos 18 anos; e

- Lucas (22 anos): início da escolarização aos 8 anos; imediatamente, foi apresentado à Libras.

Cada sessão durava, em média, 120 minutos. Elas foram videogravadas e transcritas para posterior análise. Além da transcrição, era composto um diário de campo com as impressões de cada profissional sobre as sessões.

No presente artigo, decidimos por destacar, dos dados coletados, as narrativas dos surdos sobre o processo de escolarização no Distrito Federal, na década de 1990. Esse período nos parece especialmente importante porque registra o início das políticas de inclusão voltadas para surdos. Tais políticas apresentavam contradições com relação à filosofia educacional para esse público e ambiguidades sobre o papel da escolarização na formação do sujeito surdo (Souza e Góes, 1999). Como poderá ser visto a seguir, essas problemáticas emergem na produção

3. 0 projeto foi coordenado pela primeira autora em parceria com o Prof. Ileno Izidio da Costa (UnB), tendo como pedagogo dos atendimentos o segundo autor.

4. Os nomes dos sujeitos são fictícios, com vista à preservação do anonimato dos participantes da pesquisa. 
de narrativas sobre: a) os sentimentos acerca da escola e b) os processos de escolarização dos surdos.

\section{Análise e discussão dos dados}

Para a discussão dos objetivos propostos neste trabalho, foram realizados estudos detalhados dos diários de campo e das transcrições das sessões de atendimento psicoeducacional. A partir deles, duas categorias de análise foram consideradas relevantes para a exploração da problemática suscitada: Sentimentos sobre a escola: contradições discursivas e Narrativas sobre escolarização do surdo.

Vejamos os dados:

\section{Categoria 1 - Sentimentos sobre a escola: contradições discursivas}

\section{a) Contexto enunciativo: 9 de novembro de 2010}

A atividade do dia consistia em formar uma árvore genealógica. 0 grupo (composto pela equipe multidisciplinar e os surdos Lucas, Artur e Fábio) deveria construir uma lista de sentimentos sobre as relações familiares e simbolizá-los. Desse modo, raiva era um triângulo; amor, um círculo; alegria, um retângulo etc. Após a discussão sobre a família, a psicóloga sugeriu que o grupo conversasse acerca das relações em outros contextos, como a escola, os amigos, a igreja etc., utilizando o mesmo procedimento pedagógico com as formas geométricas.

\section{b) Análise dos fragmentos discursivos}

\section{Lucas:}

“Na escola, eu colocaria o sentimento de alegria. Tem algumas brigas, o problema da comunicação, às vezes, é ruim. Havia falta de comunicação maior nas minhas séries anteriores. Na escola, eles usam essa nomenclatura 'deficiente auditivo'. Eu acho que tem que mudar, tem que tirar. Eu acho que confunde um pouco. Eles realmente tratam a gente como deficiente."

Artur (falando da escola):

“Eu acho que é alegria, pela experiência que eu tive com o diretor lele era uma pessoa muito boa)... não sei, mas acho que é alegria." 
Fábio (referindo-se à escola):

“Eu acho que é alegria. Eu vou falar um pouco do (sinaliza o nome da instituição), eu estudei lá... 0 padre proibia o uso de certas roupas indevidas, era obrigatório o uso de certas roupas."

No jogo terapêutico em que foi desenvolvida a presente pesquisa, uma prática comum entre os sujeitos pesquisados era a imitação das palavras usadas pelo outro. Nos fragmentos supracitados, alegria correspondia ao sinal utilizado para resumir o sentimento relativo à escola. É importante salientar que todos os surdos usavam o mesmo sinal para referir-se à escola. Apesar de a imitação ser um elemento positivo no processo de aquisição da linguagem, indica, por outro lado, o vocabulário limitado dos surdos adultos investigados, gerando problemas na nomeação das emoções e dos sentimentos. Muitas vezes, eles copiavam o sinal usado, pois não conheciam a forma correta de expressar suas emoções.

Num desdobramento dessa questão, emergiu uma contradição entre o que era sinalizado e o que era narrado. Apesar de o sinal alegria ser eleito para rotular as situações vividas na escola, Lucas e Fábio davam exemplos negativos sobre suas vidas acadêmicas. Percebemos, de modo geral, que sentimentos conflitantes e contraditórios indicavam o modo como os surdos tinham vivido a escola, por meio de processos de exclusão, e, consequente, do apagamento da condição bicultural.

Lucas narrou objetivamente o problema da comunicação e a sensação de ser tratado como deficiente. Ele comentou: "Na escola eles usam essa nomenclatura 'deficiente auditivo'. Eu acho que tem que mudar, tem que tirar. Eu acho que confunde um pouco. Eles realmente tratam a gente como deficiente". Na lógica oralista, o espaço escolar se transforma em um ambiente hospitalar de reabilitação. Nele, a pessoa surda se move dentro de um circuito limitado pautado pela deficiência, em que se enfatizam as limitações do sujeito. (Skliar, 2010)

Essas restrições revelam, entre outros, a experiência do surdo diante da patologização da surdez e a consequente necessidade de reabilitação. 0 audism (traduzido em Português por ouvintismo), termo cunhado nos Estados Unidos, por Tom L. Humphries, em 1975, denuncia os preconceitos e as formas de opressão vividas pelos surdos a partir do contato desigual com a comunidade ouvinte (Martins \& Klein, 2012). Nesse movimento, o processo de colonização sofrido pelos surdos tem na questão linguística seu ponto de culminância, em que se defende a correlação entre surdez e deficiência.

Fábio se remeteu às proibições institucionais: "0 padre proibia o uso de certas roupas indevidas, era obrigatório o uso de certas roupas". Em ambos os casos, o que temos é um descontentamento, uma reclamação da escola, o que se opõe à escolha do sinal alegria. 
Artur, por sua vez, pareceu vincular de forma mais adequada o sinal e a explicação sobre seu processo de escolarização. A relação com o diretor justificava a palavra alegria. Vale ressaltar aqui dois aspectos interdependentes: al as ambiguidades na caracterização dos sentimentos sobre a escola e b) as dificuldades desses surdos adultos de narrar (nomear) seus sentimentos e experiências. Nesses termos, o acesso tardio à língua de sinais, a vivência escolar oralista e o pouco contato com a cultura surda sugerem as bases explicativas para a compreensão das dificuldades de narrar o que se sente e o que foi vivido na escola. Dessa forma, defendemos, assim como Skliar (2006), Silva (2002) e Souza (1998), entre outros, a importância do acesso prematuro da criança à língua de sinais. 0 contato tardio pode restringir as práticas comunicativas, trazendo consequências negativas para o desenvolvimento cognitivo e, sobretudo, dificultando o acesso à informação e aos bens culturais.

\section{Categoria 2 - Narrativas sobre escolarização do surdo}

\section{a) Contexto enunciativo - 23 de novembro de 2010}

A equipe multidisciplinar propôs a exibição de um excerto do filme "Sou Surdo e Não Sabia (2009)". O trecho escolhido discorria acerca dos diversos modelos de educação para surdos, como escola integrada, escola/instituição oralista e escola bilíngue. Em seguida, a equipe perguntou quais aspectos do filme tinham vinculação com as experiências escolares dos surdos presentes (Lucas, Artur, Fábio, Luíza e Carlos).

\section{b) Análise dos fragmentos discursivos}

\section{Lucas:}

“Eu também cresci em meio ao oralismo, depois fui adquirindo a língua de sinais e fui me desenvolvendo. A questão do oralismo é a dificuldade das palavras, depois dos gestos, depois você adquire a língua de sinais. Eu acho melhor a língua de sinais, eu acho o oralismo muito ruim. Por exemplo, o pai insere o filho numa cultura completamente diferente, que é a cultura oralista [...], como foi na minha vida. Nós somos injustamente inseridos pela família, não temos uma escolha própria."

Artur:

“Quando a gente é criança, a gente não aprende a língua de sinais, a gente aprende o oralismo. Depois a gente vai crescendo, desenvolve e aprende a língua de sinais. Meus 
pais não sabiam que teriam um filho surdo, que não falaria e que usaria Libras, leles não sabiam) que existiria essa barreira na comunicação dentro da família. E também na escola com professores que só usam o oralismo, mas que apesar disso eu consegui."

Fábio:

"Meus pais me inseriram na cultura oralista e queriam que eu aprendesse assim como os ouvintes."

Luíza:

"Eu estudei numa escola em que a maioria era ouvinte. Eu era obrigada a falar, não ouvia, não entendia. Eu era a única surda em sala de aula. Achava muito ruim."

Carlos:

“Eu me desenvolvi... ia ao fonoaudiólogo, usava aparelho. Às vezes, minha mente, meu cérebro travava. Aprendi a desligar e tirar o aparelho. Isso me causava um bloqueio. Mas aprendi a usar minhas mãos, usar a língua de sinais. Eu considero o bilinguismo muito importante para a pessoa surda. Eu pretendo me desenvolver mais na língua de sinais para ter um desenvolvimento melhor."

Vigotski (1997), no inicio do século XX, já chamava a atenção para o fato de a educação voltada para surdos configurar-se de modo a apartá-los sistematicamente do ambiente social de forma a "a isolá-lo e situá-lo em um ambiente limitado e fechado, onde tudo está adaptado para seu defeito" (Vigotski, 1997, p. 125). Porém, dentro da sua proposta revolucionária de uma nova psicologia, o autor propõe uma reforma educacional para esse público e estabelece que o trabalho com crianças surdas precisa se organizar com base na educação social, defendendo que os processos de ensino e aprendizagem devem se configurar "como parte da vida social e como preparação para a participação da criança nesta vida". (Vigotski, 1997, p.125) Dessa forma, não fará sentido uma prática pedagógica que tenha como foco o "aprender a linguagem à margem da vida social." (Vigotski, 1997, p. 126)

Apesar de esses apontamentos e de as políticas públicas apresentarem, desde meados da década de 1990, uma tendência de compreensão da importância do uso da Libras nos espaços educacionais, as escolas se organizavam basicamente a partir dos pressupostos oralistas (Lacerda, 1996; Souza, 1996; Goldfeld, 1997. entre outros). A Libras inexistia, conforme narra Luíza, como canal privilegiado de comunicação com e entre surdos na escola. A escolarização se concentrava na oralidade, trazendo dificuldades aos processos de construção do conhecimento.

$\mathrm{Na}$ verdade, os surdos deviam se ajustar às exigências da comunidade ouvinte, conforme indica Carlos, e tinham que aprender como os ouvintes. Sobre isso, Fábio 
comenta: "(Meus pais) queriam que eu aprendesse assim como os ouvintes". Souza (1998) aponta que o oralismo defende um ajuste da surdez, por meio da aquisição da fala. Na educação de cunho oralista, a voz ocupa lugar de supremacia, sendo entendida como via de normalização e correção do corpo imperfeito.

0 aprendizado e o uso da Libras, nessa filosofia educacional, é entendido como um problema e empecilho para a integração do surdo. Muitos surdos viveram entraves sociais e cognitivos que se desdobraram em estresse, afetando suas vidas de modo profundo. Andreis-Witkoski (2009), pesquisadora surda, relata situações cotidianas de preconceito e isolamento em razão do uso língua de sinais e/ou de sua fala oralizada, reveladora de "um jeito surdo de falar" (AndreisWitkoski, 2009, p. 566). A autora também discute que a obstinação em fazer o surdo falar submete-os a situações penosas; treinamentos clínicos, especialmente os fonoaudiológicos, intermináveis.

Carlos, por exemplo, relata que usar o aparelho (ASSI) era um problema. Por isso decidiu, transgredindo as orientações clínicas do fonoaudiólogo, desligálo. Afinal, o aparelho causava-lhe um desconforto e dificuldades psicológicas de diferentes ordens. Há indícios, no relato de Carlos, de que o uso do aparelho também atrapalhava a aquisição da Libras: “(...) ia ao fonoaudiólogo, usava aparelho. Às vezes, minha mente, meu cérebro travava. Aprendi a desligar e tirar o aparelho. Isso me causava um bloqueio. Mas aprendi a usar minhas mãos, usar a língua de sinais".

Contudo, o que mais chama a atenção nos dados elencados é a ausência de escolha do surdo sobre o próprio processo de escolarização. Lucas acha “[...] o oralismo muito ruim". Ele adverte: "Nós somos injustamente inseridos pela família, não temos uma escolha própria".

É necessário problematizar que a maioria das crianças surdas cresce dentro de uma família ouvinte, que geralmente desconhece ou rejeita a língua de sinais, desenvolvendo no seio familiar um sistema de comunicação gestual. Esse sistema, porém, é muito limitado para interações, e não conduz a criança surda a um processo formal de aquisição de informações linguísticas e socioculturais (Skiliar, 2006). Por causa disso, muitas vezes, conforme aponta Ribeiro (2011), os surdos ocupam uma posição de meros observadores da vida familiar. De fato, a não fluência em Libras entre os familiares causa distanciamentos, interações não frequentes e conversas restritas.

Para os surdos, como pode ser observado nas narrativas, o oralismo não era, de fato, uma opção educacional - nem mesmo esfera linguística, que garantia o pertencimento à sociedade majoritária, ou seja, sua inclusão social. De modo geral, os surdos foram sendo levados pelas escolhas externas (familiares), driblando com dificuldade as barreiras linguísticas e curriculares (possivelmente, avaliativas) que se impuseram durante a escolaridade. Tardiamente, encontraram a língua de 
sinais. Artur comenta: "Depois a gente vai crescendo, desenvolve e aprende a língua de sinais". Nessa linha, Carlos ressalta: "Eu pretendo me desenvolver mais na língua de sinais para ter um desenvolvimento melhor".

Fica evidente, ao analisar as narrativas, o quão penoso foi para os sujeitos pesquisados se adequarem às exigências médico-pedagógicas pautadas em pressupostos que entendem a fala oral como a única via comunicativa. Conforme o relato de Luíza: "eu era obrigada a falar, não ouvia, não entendia", a técnica oralista resultou na aprendizagem de uma língua ausente de sentido; uma língua morta, artificial e inútil para o estabelecimento de intercâmbios comunicativos relevantes. Nesse sentido, a defesa de Vigotski (1997) parece pertinente e se coaduna com as vozes dos surdos. 0 autor afirma: "um método pode ser maravilhoso, mas se ele força-nos a tratar o aluno cruelmente, se não resulta em linguagem significativa, é preciso abandoná-lo." (Vigotski, 1997, p. 124)

0 fracasso do oralismo não é uma grande novidade. Muitos estudos já avançaram com o intuito de demonstrar como as tais práticas trouxeram prejuízos para o processo de escolarização dos surdos (Góes, 2002; Souza, 1998; Silva, 2002; Lacerda, 2006; entre outros). Contudo, aqui, queremos ressaltar o impacto que tais processos tiveram na vida dessas pessoas a partir da experiência com a memória e a narrativa que entrevê, nesse caso, uma forma peculiar de constituição subjetiva.

Conforme discutimos anteriormente, a narrativa possiblita uma função entre o nós e o eu; um encontro entre a biografia com as vidas. Se, por um lado, esses relatos revelam a história acadêmica de um grupo de surdos, é possível depreender teoricamente que essa história qualifica e dá visibilidade à narrativa de outros surdos. Nesse caso, importa-nos salientar a experiência de fracasso e sofrimento que caracterizou os processos de escolarização dos sujeitos pesquisados, marcando-os até a vida adulta.

Trata-se, portanto, de olhar para esse processo de escolarização e revelar, para além dos problemas acadêmicos advindos de uma escolarização excludente, aspectos emocionais que marcaram os surdos pesquisados. Eles não podiam aprender em sua língua natural, nem sequer compartilhar da escolha dos espaços institucionais (sejam clínicos, sejam escolares) de que iriam participar. A lembrança desses surdos, presentificada em suas narrativas, revela experiências de desempoderamento e de configuração de um lugar social de dependência frente às demandas da comunidade oral. Essa questão diz respeito aos professores e demais profissionais que atuam diretamente com o surdo, especialmente, nas escolas. 


\section{Considerações finais}

Evidenciamos, neste trabalho, o papel da memória e da narrativa no desenvolvimento ontogenético e sua relação com a história e a cultura. A partir daí, entretecemos tais considerações teóricas com os processos de escolarização dos surdos, em especial, o impacto da transição das políticas educacionais na formação acadêmica de jovens surdos do Distrito Federal (da ênfase oralista para as propostas bilinguistas e/ou inclusivas).

O foco de análise foi a produção de narrativas sobre os últimos vinte anos de escolarização, revelando a importância do acesso à língua de sinais e seu forte efeito no desenvolvimento acadêmico dos sujeitos pesquisados. De fato, estudar as narrativas de indivíduos surdos se configura como importante subsídio para fundamentar a construção de políticas públicas educacionais voltadas para esse público.

Como pôde ser visto na análise dos dados, a aquisição tardia da língua de sinais e o pouco contato com a cultura surda, decorrente de uma pressão familiar de submissão à comunidade ouvinte, acarretaram prejuízos nos processos formativos e no desenvolvimento cognitivo/simbólico dos sujeitos pesquisados. Por outro lado, o exercício enunciativo de pensar e narrar a própria história (biografias pesquisadas) permitiu a emergência das vozes dos surdos sobre suas impressões acerca da escolarização a que foram submetidos. De acordo com Vieira-Machado (2007), essas informações trazem para o campo discursivo saberes outrora subalternizados e histórias até então silenciadas, estabelecendo um espaço profícuo de investigação da história da educação de surdos.

Concluímos que os surdos investigados lem fase final do processo de escolarizaçãol viveram um complexo mecanismo de exclusão social, pois as políticas públicas vigentes, que tentaram minimizar as desigualdades no acesso aos bens culturais, institucionais e políticos, não preencheram as lacunas deixadas pelo passado oralista. Esse vácuo formativo se pautou em uma perversidade ideológica que produziu um “[...] holocausto linguístico, cognitivo e cultural" (Skliar, 2010, p. 16) que acometeu parte considerável dos surdos jovens e adultos. Eles, hoje, precisam ser pesquisados e atendidos de forma particular, pois suas demandas são próprias e devem ser resolvidas com políticas inclusivas sensíveis ao seu drama pessoal e acadêmico. 


\section{Referências}

ANDRÉ, Marli Elisa D. A. de. Etnografia da prática escolar. São Paulo: Papirus, 2002.

ANDREIS-WITKOSKI, Sílvia. Surdez e preconceito: a norma da fala e o mito da leitura falada. Revista Brasileira de Educação, v. 14, p. 565-576, 2009.

BEHARES, Luis Ernesto. Nuevas corrientes em la educación del sordo: de los enfoques clínicos a los culturales. Cadernos de Educação. Universidade Federal de Santa Maria, n. 04, 1989.

GÓES, Maria Cecília Rafael de. Linguagem, surdez e educação. 3. ed. rev. Campinas, SP: Autores Associados, 2002.

GOLDFELD, Márcia. A criança surda: linguagem e cognição numa perspectiva sócio-interacionista. São Paulo: Plexus, 1997.

HALBWACHS, Maurice. A memória coletiva. São Paulo: Edições Vértice, 1990. KELMAN, Celeste Azulay. Multiculturalismo e surdez: uma questão de respeito às culturas minoritárias. In: FERNANDES, Eulália (Org.). Surdez e bilinguismo. 5. ed. Porto Alegre: Mediação, 2012. p. 87-103.

KRAMER, Sônia. Linguagem e tradução: um diálogo com Walter Benjamin e Mikhail Bakhtin. In: FARACO, Carlos Alberto; TEZZA, Cristovão; CASTRO, Gilberto. (Org.). Diálogos com Bakhtin. 4 ed. Curitiba: UFPR, 2007. p. 177-191. LACERDA, Cristina Broglia Feitosa de. A inclusão escolar de alunos surdos: 0 que dizem alunos, professores e intérpretes sobre esta experiência. Cadernos CEDES, Campinas, v. 26, n. 69, Ago. 2006.

LOPES DE OLIVEIRA, Maria Cláudia Santos Lopes de. Narrativas e desenvolvimento da identidade profissional de professores. Cadernos CEDES, Campinas, v. 32, n. 88, dez. 2012.

MARTINS, Francielle Cantarelli; KLEIN, Madalena. Estudos da contemporaneidade: sobre ouvintismo/audismo. In: IX ANPED SUL - Seminário de Pesquisa em Educação da Região Sul, 2012, Caxias do Sul. Anais..., 2012. v. 1. p. 1-15.

PERLIN, Gladis Terezinha. O lugar da Cultura Surda. In: THOMA, Adriana da Silva, LOPES, Maura Corcini (Org). A invenção da surdez: cultura, alteridade, identidade e diferença no campo da educação. Santa Cruz do Sul: EDUNISC, 1. reimpressão, 2005.

PERLIN, Gládis Terezinha. Identidades Surdas. In: SKLIAR, Carlos (org). A surdez: um olhar sobre as diferenças. 4. ed. Porto Alegre: Mediação, 2010.

RIBEIRO, Karen. Sexualidade e gênero: estudo das relações afetivas de jovens surdas de uma escola municipal de educação especial de São Paulo. Tese (Doutorado em Educação). Programa de Pós-graduação em Educação, 
Universidade de São Paulo, 2011.

SANCHÉZ, Carlos. La educación de los sordos en un modelo bilingue. Mérida, Venezuela, 1991.

SILVA, Daniele Nunes Henrique. Como brincam as crianças surdas. 2. ed. São Paulo: Plexus, 2002.

SILVA, Daniele Nunes Henrique; SIRGADO, Angel Pino; TAVIRA, Larissa Vasques. Memória, narrativa e identidade profissional: analisando memoriais docentes. Cadernos CEDES, Campinas, v. 32, n. 88, dez. 2012.

SILVA, Daniele Nunes Henrique. Surdez e inclusão social: o que as brincadeiras infantis têm a nos dizer sobre esse debate? Cadernos CEDES, Campinas, v. 26, n. 69, ago. 2006.

SILVA, Daniele Nunes Henrique. Como brincam as crianças surdas. 2. ed. São Paulo: Plexus, 2002.

SKLIAR, Carlos. Uma perspectiva sócio-histórica sobre a psicologia e a educação de surdos. In: SKLIAR, Carlos (Org.). Educação e exclusão: abordagens sócioantropológicas em educação especial. 5. ed. Porto Alegre: Mediação, 2006.

SKLIAR, Carlos. Os estudos surdos em educação: problematizando a normalidade. In: SKLIAR, Carlos (Org.) A surdez: um olhar sobre as diferenças. 4. ed. Porto Alegre: Mediação, 2010.

SMOLKA, Ana Luiza Bustamante. A memória em questão: uma perspectiva histórico-cultural. Educação e Sociedade, Campinas, v. 21, n. 71, July 2000.

SOUZA, Regina Maria de. Que palavra que te falta? O que o surdo e a lingua(gem) de sinais têm a dizer à lingüística e a educação. Tese (Doutorado em Linguística). Programa de Pós-Graduação em Linguística. Universidade Estadual de Campinas, 1996.

SOUZA, Regina Maria de. Língua de sinais e língua majoritária como produto de trabalho discursivo. Cadernos CEDES, v. 19, n.46, p. 57-67, 1998

VIEIRA-MACHADO, Lucyenne. As narrativas surdas: da história da resistência a uma proposta educacional atual. Revista da Feneis, v. 1, p. 16-19, 2007.

VIGOTSKI, Lev Seminovich. Fundamentos de defectologia: obras escogidas/tomo cinco. Madrid: Visor, 1997

VIGOTSKI, Lev Seminovich. Manuscrito de 1929. Educação e Sociedade, Campinas, v. 21, n. 71, jul. 2000. 
Recebido em julho de 2013

Aprovado março de 2014

Daniele Nunes Henrique Silva é doutora em Educação pela Universidade Estadual de Campinas (Unicamp) e professora do Programa de Pós-Graduação em Processos de Desenvolvimento Humano e Saúde da Universidade de Brasília (UnB) e do Departamento de Psicologia Escolar e Desenvolvimento do Instituto de Psicologia (UnB). E-mail: daninunes74dgmail.com

Fabrício Santos Dias de Abreu é pedagogo formado pela Faculdade de Educação da Universidade de Brasília (UnB) e mestrando em Processos de Desenvolvimento Humano e Saúde do Instituto de Psicologia (UnB). E-mail: fabra201ahotmail.com 